\title{
Prevalence of Traumatic Findings on Routine MRI in a Large Cohort of Professional Fighters
}

\author{
(D).K. Lee, (D). Wu, DS. Banks, (D) C. Bernick, DM.G. Massand, (DM.T. Modic, (DP. Ruggieri, and (D).E. Jones
}

\begin{abstract}
BACKGROUND AND PURPOSE: Previous studies investigating MR imaging abnormalities among fighters have had small sample sizes. This investigation assessed a large number of fighters using the same conventional sequences on the same scanner.
\end{abstract}

MATERIALS AND METHODS: Conventional 3T MR imaging was used to assess 499 fighters (boxers, mixed martial artists, and martial artists) and 62 controls for nonspecific WM changes, cerebral microhemorrhage, cavum septum pellucidum, and cavum vergae. The lengths of the cavum septum pellucidum and cavum vergae and the ratio of cavum septum pellucidum to the septum pellucidum lengths were assessed.

RESULTS: The prevalence of nonspecific WM changes was similar between groups. Fighters had a prevalence of cerebral microhemorrhage ( $4.2 \%$ versus $0 \%$ for controls, $P=.152$ ). Fighters had a higher prevalence of cavum septum pellucidum versus controls ( $53.1 \%$ versus $17.7 \%, P<.001)$ and cavum vergae versus controls (14.4\% versus $0 \%, P<.001)$. The lengths of the cavum septum pellucidum plus the cavum vergae $(P<.001)$, cavum septum pellucidum $(P=.025)$, and cavum septum pellucidum to the septum pellucidum length ratio $(P=.009)$ were higher in fighters than in controls. The number of fights slightly correlated with cavum septum pellucidum plus cavum vergae length $(R=0.306, P<.001)$ and cavum septum pellucidum length $(R=0.278, P<.001)$. When fighters were subdivided into boxers, mixed martial artists, and martial artists, results were similar to those in the whole-group analysis.

CONCLUSIONS: This study assessed MR imaging findings in a large cohort demonstrating a significantly increased prevalence of cavum septum pellucidum among fighters. Although cerebral microhemorrhages were higher in fighters than in controls, this finding was not statistically significant, possibly partially due to underpowering of the study.

ABBREVIATIONS: $\mathrm{CMH}$ = cerebral microhemorrhage; $\mathrm{CSP}=$ cavum septum pellucidum; $\mathrm{CSPV}=$ cavum septum pellucidum and vergae; $\mathrm{CV}=$ cavum vergae; NSWMC = nonspecific white matter change; $\mathrm{MA}=$ martial artists; $\mathrm{MMA}=$ mixed martial artists; PFBHS = Professional Fighters Brain Health Study

M ultiple sports such as boxing, mixed martial arts, football, and soccer involve repetitive head trauma in young people, and this trauma is accumulated over many years. Many studies have attempted to describe conventional MR imaging findings associated with repetitive head trauma in the hope that an early in vivo diagnosis may preclude further trauma and help guide possible treatment. ${ }^{1-9}$ However, these studies have often involved a small number of athletes, leading to variable findings and a low significance of results. ${ }^{10,11}$ In some

Received July 20, 2016; accepted after revision February 10, 2017.

From the Imaging Institute (J.K.L., J.W., M.G.M., M.T.M., P.R., S.E.J.) and Lou Ruvo Center for Brain Health (S.B., C.B.), Cleveland Clinic, Cleveland, Ohio.

This work was supported by HBO, the Lincy Foundation, Ultimate Fighting Championship, Spike TV/Bellator MMA, Top Rank Promotions, Golden Boy Promotions, the August Rapone Family Foundation, and Haymon Boxing.

Please address correspondence to Jonathan K. Lee, MD, Imaging Institute, Cleveland Clinic, 9500 Euclid Ave, L10, Cleveland, OH 44195; e-mail: leej13@ccf.org

http://dx.doi.org/10.3174/ajnr.A5175 studies, MR imaging results were normal for athletes with head trauma, ${ }^{7,9}$ whereas other studies demonstrated a variably increased prevalence of cerebral microhemorrhage $(\mathrm{CMH}),{ }^{4,5}$ nonspecific WM changes (NSWMCs), ${ }^{11}$ or cavum septum pellucidum (CSP)/cavum septum pellucidum and vergae (CSPV). ${ }^{1,2,10}$

Regarding professional fighting, previous studies have similarly demonstrated the occurrence of imaging abnormalities, with imaging findings ranging from smaller volumes in structures such as the thalamus, vermis, and hippocampus and microhemorrhages in the parenchyma to macrohemorrhages such as subdural hematomas and parenchymal contusions. ${ }^{4-6,8,12,13}$ However, these studies were also limited by small sample sizes and a relatively low prevalence of microhemorrhages, so the calculated increased prevalence was not found to be statistically significant. ${ }^{4,5}$

Other studies have demonstrated a higher incidence of CSP among fighters, with some research finding a trend toward significance in fighters versus controls. ${ }^{10}$ However, an early large study 
of fighters demonstrated increased CSP prevalence in controls rather than in fighters. ${ }^{3}$ More recent studies in retired professional American football players found that the prevalence and size of the CSP were increased in the athletes versus controls. ${ }^{2,14}$ Comparing these studies is complicated by differences in patient populations (eg, different sports, various age groups, current athletes versus retired athletes). ${ }^{2,4,5,14}$ Additionally, even though an increased prevalence of CSP has been demonstrated among fighters in previous research, neuroradiologists disagree over whether this is a manifestation of trauma or simply a normal variant.

Other conventional MR imaging findings in patients with repetitive head trauma include the presence of NSWMCs. ${ }^{7}$ However, some research into repetitive head trauma has demonstrated normal imaging findings in these patients. ${ }^{11}$ This finding is consistent with our anecdotal experience.

In this study, we chose to focus on a sport with a known high incidence of repetitive head trauma (professional fighters), using a large sample size and ensuring that all fighters were scanned with the same protocol on the same $3 \mathrm{~T}$ MR imaging scanner. We sought to assess the prevalence of NSWMCs, CMH, and CSP/ CSPV among these fighters versus the prevalence of these imaging abnormalities among healthy controls.

\section{MATERIALS AND METHODS Fighter Population}

The Professional Fighters Brain Health Study (PFBHS) is an ongoing observational study of active professional fighters (boxers, mixed martial artists [MMA], and martial artists [MA] fighters), retired professional fighters, and age-matched healthy controls. ${ }^{15}$ This study was approved by the local institutional review board, and informed consent was obtained from all participants. The purpose of this study is to follow imaging and psychological metrics across time as fighters practice their craft and experience repetitive head trauma, allowing researchers to explore the relationships among head trauma exposure, changes in brain imaging, and neurologic/behavioral functioning. However, this article only focuses on conventional imaging findings between fighters and controls at the current time. Further correlations between imaging findings and neurologic/behavioral functioning and longitudinal follow-up of imaging findings are currently being investigated.

Fighters eligible for enrollment in the PFBHS were those who hold a license to fight professionally. Study patients were required to be at least 18 years of age, with at least a fourth-grade reading level, fluency in English or Spanish, and a willingness to undergo annual evaluations, including 3T MR imaging, neurocognitive testing, and blood sampling for genotyping and exploratory biomarker studies. We obtained extensive details about fighting history for all study patients before performing MR imaging, including information about the type of fighting (boxing or mixed martial arts), the number of fights, years of fighting, and the number of knockouts.

The PFBHS control group included age- and sex-matched participants without a history of head trauma or participation in a sport associated with head injuries at a high school level or beyond. A medical history was self-reported by both the fighters and controls, including any diagnosed medical conditions, all medications, performance-enhancing drugs, and other drug use.

\section{MR Imaging Acquisition}

All participants were scanned on a Verio 3T system (Siemens, Erlangen, Germany). Conventional sagittal 3D MPRAGE T1 (voxel size $=1 \times 1 \times 1.2 \mathrm{~mm}, \mathrm{TR} / \mathrm{TE} / \mathrm{TI}=2300 / 2.98 / 900 \mathrm{~ms}$, scan time $=9$ minutes 14 seconds), axial TSE T2 (voxel size $=$ $0.8 \times 0.8 \times 4 \mathrm{~mm} \mathrm{TR} / \mathrm{TE}=5000 / 2.98 \mathrm{~ms}, 38$ sections, scan time $=57$ seconds), axial TSE FLAIR (voxel size $=0.8 \times 0.8 \times 4$ $\mathrm{mm}, \mathrm{TR} / \mathrm{TE} / \mathrm{TI}=7000 / 81 / 2220 \mathrm{~ms}, 38$ sections, scan time $=2$ minutes 36 seconds), and axial SWI (voxel size $=0.9 \times 0.9 \times 0.9$ $\mathrm{mm}, \mathrm{TR} / \mathrm{TE}=20 / 27 \mathrm{~ms}, 36$ sections, scan time $=1$ minute 17 seconds) sequences were used for this study. These sequences were evaluated for the presence of $\mathrm{CMH}, \mathrm{CSP}$, and NSWMC. The scans were assessed for the presence of $\mathrm{CMH}$ by 4 neuroradiologists (experience: M.T.M., 38 years; S.E.J., 10 years; M.G.M., 10 years; and P.R., 24 years) and a neuroradiology fellow. Initial disagreements were resolved by consensus. A neuroradiology fellow and a radiology resident assessed the scans for the presence of CSP, and a neuroradiology fellow assessed the scans for the presence of NSWMC. The raters were blinded to whether the images belonged to fighters or controls.

\section{Image Analysis}

NSWMCs were defined as focal areas of T2 and FLAIR signal hyperintensity relative to the adjacent WM in 1 of 3 subregions: subcortical, deep, and periventricular WM. NSWMC foci were excluded if they were $<3 \mathrm{~mm}$ or if they were associated with another abnormality such as a microhemorrhage or encephalomalacia. NSWMCs were defined as absent, punctate foci, the beginning of coalescence, or large areas of coalescence based on the Fazekas score. ${ }^{16}$

CMHs were defined as well-defined areas of abnormal susceptibility hypointensity that were focal, rounded, $<5 \mathrm{~mm}$, not on the pial or ependymal surface, and not due to vessel or normal variant anomalies such as developmental venous anomalies. Cavernous malformations were also excluded from this definition on the basis of characteristic features seen on SWI and T2 sequences.

CSP was defined and measured in a manner similar to that used in recently published studies on retired professional American football players. ${ }^{2,14}$ A CSP was defined as a cystic space between the 2 leaflets of the preforniceal septum pellucidum as viewed on coronal 3D MPRAGE T1-weighted images and whose signal characteristics followed those of CSF. Continuation of the cyst into the postforniceal septum was termed a cavum vergae (CV). The length and transverse diameter of the CSP and/or $\mathrm{CV}$ were measured on axial reconstructed T1 images crossreferenced to the last coronal image on which the CSP was seen (Fig 1). If the cystic space measured $\leq 1 \mathrm{~mm}$ in length, it was not counted as a CSP. To account for possible increased size of the CSP with increased head and ventricular size, we measured the septum pellucidum on sagittal T1 imaging from the dorsal margin of the genu of the corpus callosum to the ventral margin of the splenium and calculated a ratio of CSP length to septum length (Fig 1).

All images were reviewed by using an IMPAX 6.6 DICOM viewer (Agfa, Mortsel, Belgium) on flat panel LCD monitors. 


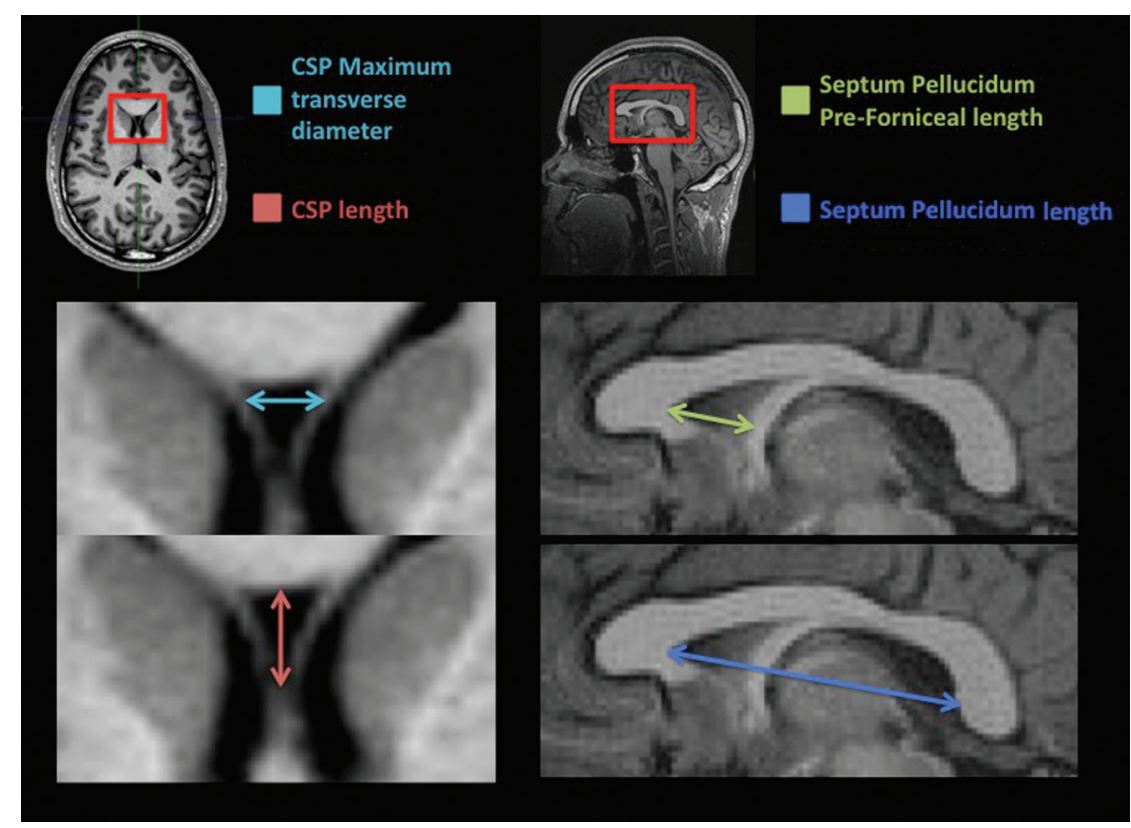

FIG 1. Example of CSP and septum pellucidum measurements.

Imaging findings in fighters and controls

\begin{tabular}{lccc}
\hline Imaging Findings & $\begin{array}{c}\text { Fighters }\left(\boldsymbol{n}=\mathbf{4 9 9 ^ { \mathrm { a } }}\right) \\
(\mathbf{N o})(\mathbf{\%})\end{array}$ & $\begin{array}{c}\text { Controls }(\boldsymbol{n}=\mathbf{6 2}) \\
(\text { No.) })\end{array}$ & $\boldsymbol{P}$ Value \\
\hline NSWMC & $118(23.6)$ & $12(19.4)$ & .525 \\
CMH & $21(4.2)$ & $0(0)$ & .152 \\
CSP & $265(53.1)$ & $11(17.7)$ & $<.001$ \\
CV & $72(14.4)$ & $0(0)$ & $<.001$ \\
\hline
\end{tabular}

${ }^{a}$ Except for $\mathrm{CMH}$, which had 498 because 1 fighter did not have SWI.

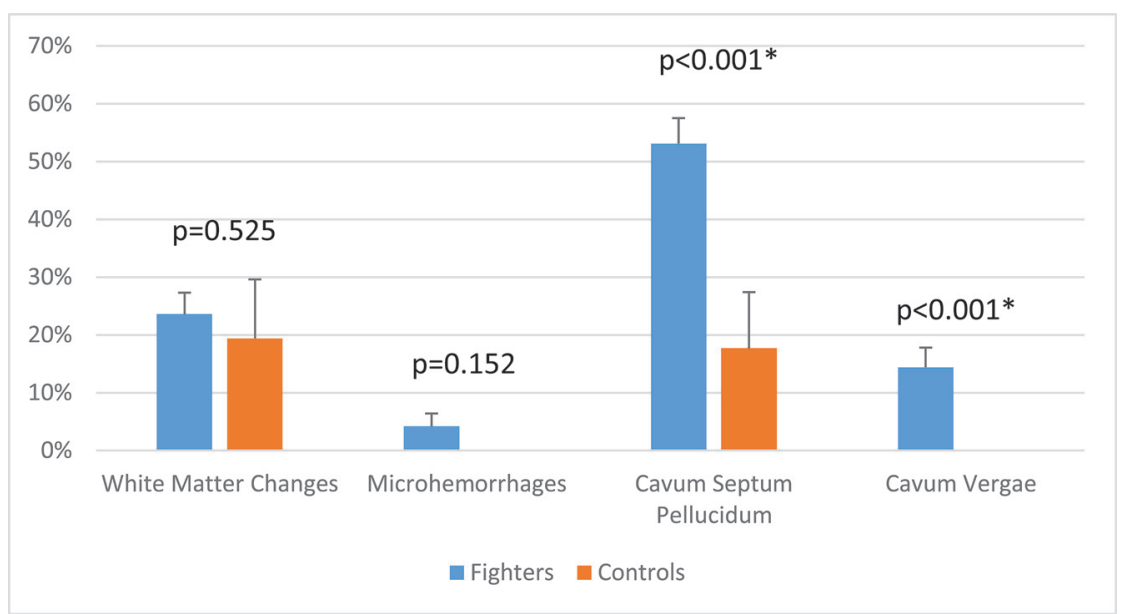

FIG 2. Prevalence of MR imaging findings in fighters versus controls.

\section{Statistical Analysis}

All statistics were calculated by using SPSS (IBM, Armonk, New York). The prevalence of CMHs, CSP, and NSWMCs was compared between the 2 groups by using a $\chi^{2}$ test, and the extent of these findings was compared with the Fisher exact test. A 2-sided $\chi^{2}$ test was used to test the hypothesis that fighters would have a greater prevalence of NSWMCs, CMHs, and CSPs than the control group. Given the low percentages of $\mathrm{CMH}$, a post hoc power analysis was also performed.

Subsequently, fighters were also subdivided into boxers, mixed martial artists, and martial artists. The total number of fighters in the subgroups does not equal the total number of fighters because some fighters have multiple fighting styles and they were not included in the subanalysis. A 2-sided $\chi^{2}$ test was used to compare the incidence of NSWMC, CMH, and CSPV in each subgroup compared with controls and subsequently with each other subgroup.

The Student $t$ test was used to compare the number of fights for fighters with CSP, CV, CMHs, or NSWMC versus the number of fights for fighters without these abnormalities. The Student $t$ test was also used to compare septum pellucidum length, CSP length, CV length, CSPV length, and CSP to septum pellucidum ratio in fighters versus controls. The Pearson correlation was used to identify any association between the number of fights and CSP or CSPV length.

\section{RESULTS}

Four hundred ninety-nine fighters and 62 controls from the PFBHS were assessed for evidence of NSWMC, CMH, and CSPV. Fighters had a mean age of 30 years and controls had a mean age of 31 years $(P=.406)$. Four hundred sixtytwo fighters were male (92.6\%), while 37 fighters were female. Fifty-six (90.3\%) controls were men, while 6 controls were women $(P=.457)$.

NSWMCs were present in $118 / 499$ (23.6\%) fighters and 12/62 (19.4\%) controls $(P=.525$; Table and Fig 2$)$. CMHs were present in $21 / 498$ (4.2\%, 1 fighter did not have SWI) fighters and $0 / 62$ controls $(0 \%, P=.152)$ (Table and Fig 3 as an example). Post hoc power analysis with an $\alpha$ of .05 showed a power (1- $\beta$ ) of $18.5 \%$. CSP was present in $265 / 499$ (53.1\%) fighters and 11/62 (17.7\%) controls $(P<.001)$ (Table). CV was present in $72 / 499(14.4 \%)$ fighters and $0 / 62$ $(0 \%)$ controls $(P<.001)$ (Table).

Twenty fighters had SWI abnormalities that the 4 neuroradiologists believed, in consensus, to be cases of cavernous malformation, capillary telangiectasia, or vascular structures such as developmental venous anomalies. If these normal variants had been included in the count of CMHs, 41 (7.9\%) fighters and 3 controls (4.8\%) would have been assessed as having positive findings on SWI.

We identified 59 CMHs: One fighter had 14 CMHs, 1 fighter AJNR Am J Neuroradiol 38:1303-10 Jul 2017 www.ajnr.org 
had 10, and the remaining $35 \mathrm{CMHs}$ were found in 19 fighters (mean, 1.5 CMHs per fighter) (Fig 4). Almost all CMHs were located near the cortex, with only a few in the deep white matter and periventricular margins. In the posterior fossa, most cases of $\mathrm{CMH}$ were in the inferior aspects of the cerebellum. There were relatively few $\mathrm{CMHs}$ in the supraorbital convexities, deep gray matter, or corpus callosum.

Figure 5 shows the distribution of NSWMCs overlaid on a sketch of representative axial brain sections. Five controls were randomly selected from among the controls for NSWMC, with a total of 15 foci. For visual comparison, 5 fighters were randomly selected from among the fighters with NSWMC. This subset of fighters showed a total of 12 foci. Not included were 2 fighters with a very large number of NSWMCs, one with approximately 30 foci and the other with approximately 20 foci. All foci were in subcortical locations, except for 2 foci that were in periventricular locations.

Fighters with NSWMC and those with CSP trended toward having a higher average of total fights (60 fights versus 46 in those

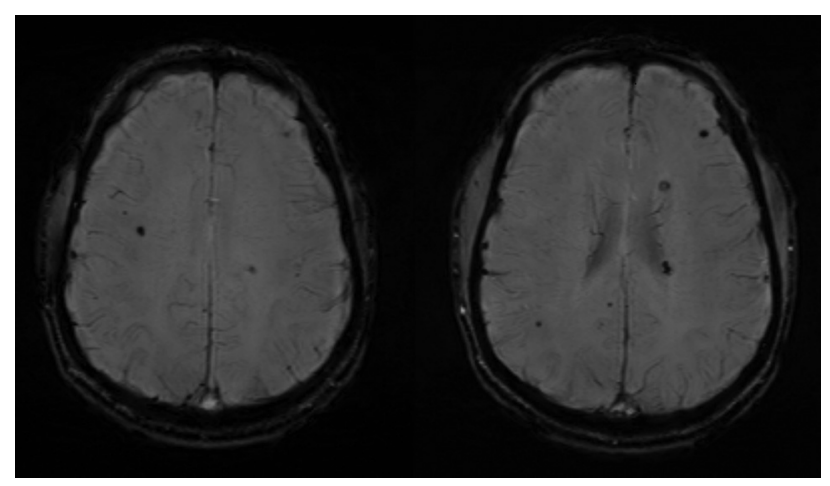

FIG 3. Example of cerebral microhemorrhage in a fighter.
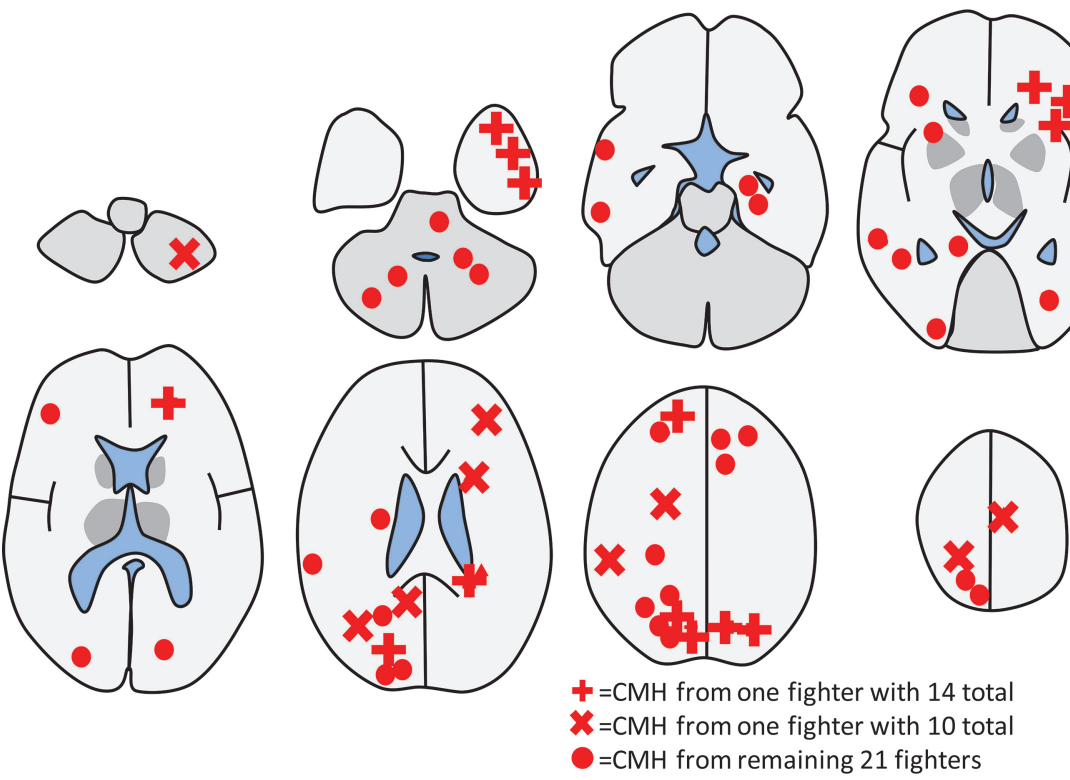

FIG 4. Schematic diagram showing the location of all cerebral microhemorrhages observed from all 21 fighters in the study. Although $50 \mathrm{CMHs}$ were observed, 2 fighters had a disproportionate share, and their $\mathrm{CMHs}$ have their own symbol of a cross and a triangle. The simplified diagram does not show all the sulci. Most CMHs were actually located near the cortex, and a few were located in the deep white matter.

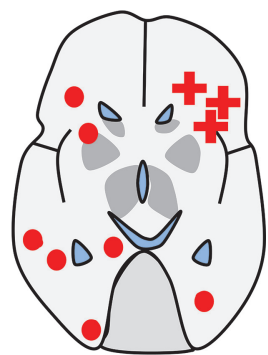

without NSWMCs, $P=.098 ; 56$ versus 42 in those without CSP, $P=.054$ ) (Fig 6). Fighters with $\mathrm{CMH}$ had a higher average of total fights than those without $\mathrm{CMH}$, though this was not statistically significant (85 versus $47, P=.530$ ), and fighters with CV had a significantly higher number of total fights than those without $\mathrm{CV}$ ( 88 versus $43, P<.001$ ).

The length of the septum pellucidum was not significantly different between fighters and controls (50.8 versus $52.4 \mathrm{~mm}, P=$ .180 ); this finding suggests that head sizes were similar between the 2 groups (Fig 7). The lengths of the CSP and CSPV were both significantly higher in fighters than in controls. In fighters with CSP, the average length was 10.9 versus $7.6 \mathrm{~mm}$ in controls $(P=.025)$ (Fig 7$)$; in fighters with CSPV, the average length was 16.2 versus $7.6 \mathrm{~mm}$ in controls $(P<.001)$. The ratio of CSP to septum length was similarly higher in fighters than in controls ( 0.21 versus $0.14, P=.009$ ) (Fig 8 ). The maximum transverse diameter of the CSP was similar for fighters and controls (3.7 versus $2.8 \mathrm{~mm}, P=.107$ ). There was a small-but-positive correlation between the number of fights and CSPV/CSP length; specifically, as the number of fights increased, the CSPV length $(R=0.306 ; P<.001)$ and CSP length $(R=0.278$; $P<.001)$ both increased slightly.

After we subdivided the fighters into boxers, MMA, and MA and compare them with controls, NSWMCs were present in 52 (27.4\%) of 190 boxers $(P=.242), 42(21.1 \%)$ of 199 MMA ( $P=$ $.859)$, and $5(17.2 \%)$ of $29 \mathrm{MA}(P=1.0)$. CMHs were present in 6 $(3.2 \%)$ of 189 boxers ( 1 boxer did not have SWI, $P=.341$ ), 12 $(6 \%)$ of 199 MMA $(P=.075)$, and $0(0 \%)$ of 29 MA. CSPs were present in $122(64.2 \%)$ of 190 boxers $(P<.001), 88(44.2 \%)$ of 199 MMA $(P<.001)$, and $14(48.3 \%)$ of $29 \mathrm{MA}(P=.005)$. CV were present in $52(27.4 \%)$ of 190 boxers $(P<.001), 12(6 \%)$ of $199 \mathrm{MMA}(P=.075)$, and $1(3.4 \%)$ of $29 \mathrm{MA}(P=.319)$.

When we compared the groups of fighters, boxers had significantly more CSP $(64.2 \%$ versus $44.2 \%$, $P<.001)$ and $\mathrm{CV}(27.4 \%$ versus $6 \%$, $P<.001)$ than MMA and more CV (27.4\% versus $3.4 \%, P=.004)$ than MAs. No significant differences were seen between MMA and MA.

\section{DISCUSSION}

This study presents a large number of fighters who have been exposed to known cumulative head trauma and scanned on the same 3T MR imaging machine by using standardized conventional imaging protocols. We found that CSP and CV occurred more frequently in fighters than in age- and sex-matched controls, whereas there was no statistical difference between groups in the occurrence of NSWMCs. $\mathrm{CMHs}$ occurred more frequently in fighters than controls, but this was not statistically significant.

The presence of $\mathrm{CMH}$ as a distinct pathologic finding was first discussed in $1924^{17}$ and was soon related to a theory 


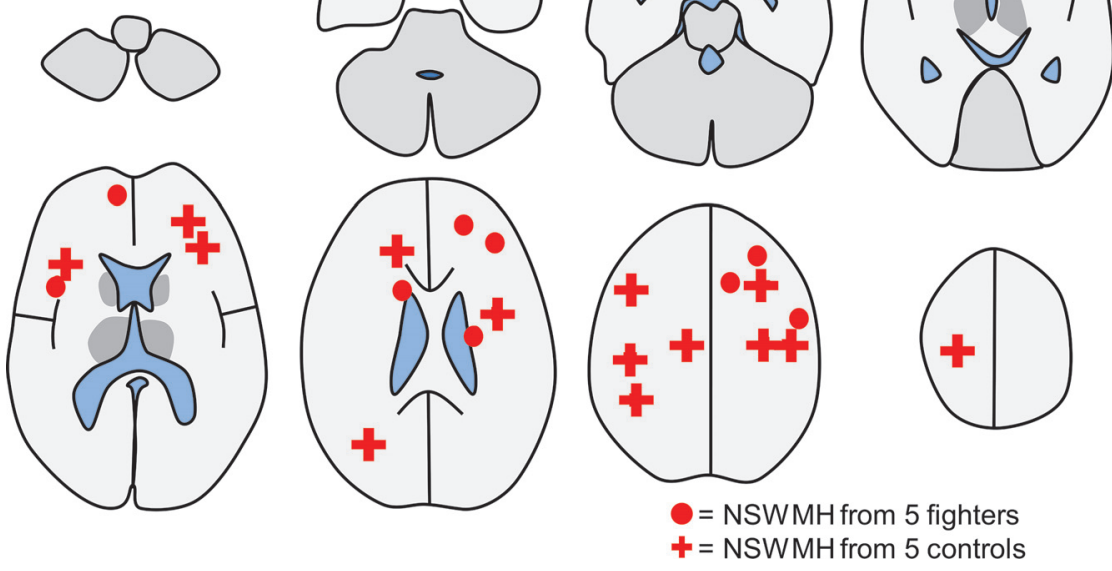

FIG 5. Schematic diagram showing the location of all 15 nonspecific white matter changes observed from 5 randomly selected controls with foci shown by crosses. For comparison of the distribution, 5 randomly selected fighters with NSWMC are shown by circles, which totaled 12 . As in Fig 4, the simplified diagram does not show all the sulci, most NSWMCs were actually located near the cortex, and only 2 were located in the periventricular margins.

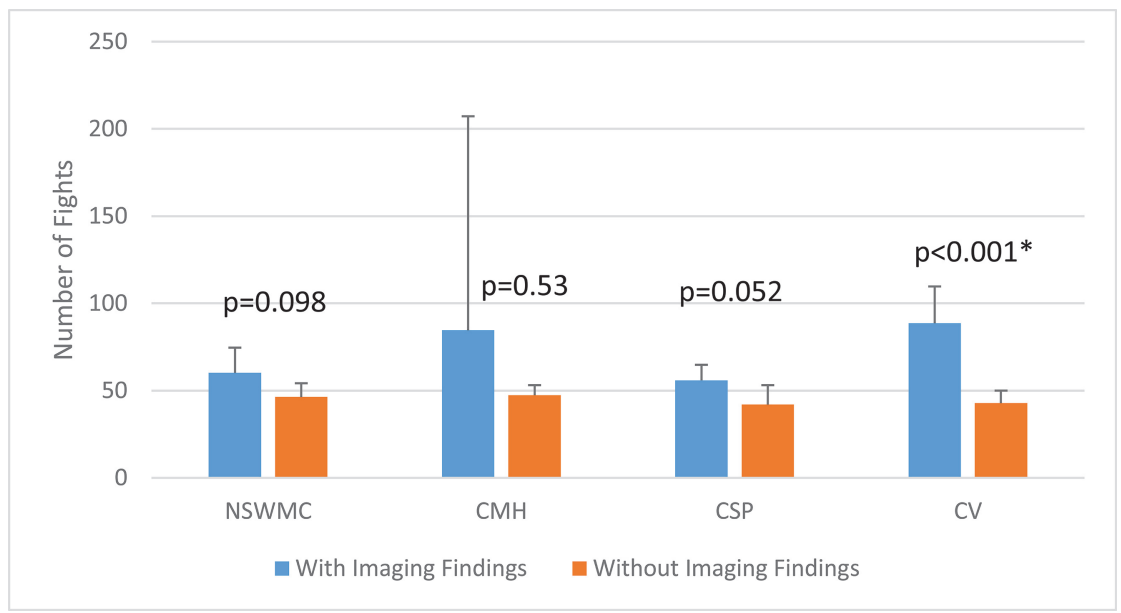

FIG 6. The number of fights in fighters with and without cavum septum pellucidum, cavum vergae, cerebral microhemorrhages, and nonspecific white matter change.

of traumatic brain injury characteristically seen in boxers. ${ }^{18}$ Mechanisms of traumatic injury at the microscopic level involve strain (relative stretch) of neural tissue, and the severity of injury depends on the magnitude of the strain. At the smallest magnitude, tissue is elastic and there is no damage; at intermediate magnitudes, there are transient and reversible alterations of membrane potentials (concussions); at the highest magnitudes, irreversible damage and chronic change occur. Along this spectrum are concomitant tissue reactions, including vasogenic and cytotoxic edema (seen acutely on DWI), microhemorrhages (seen chronically on SWI), and focal gliosis and demyelination (seen chronically on FLAIR). Because the fighters in this study were not imaged in the acute setting, imaging findings would likely be manifest as chronic changes on SWI and FLAIR.

Although the reason for microhemorrhages occurring in fighters may seem self-evident, the relatively low prevalence of
$\mathrm{CMH}$ might be surprising given the large number of fighters known to receive knockout blows and concussions. In fact, the radiologic appearance of the brain among most fighters with known multiple concussions is normal on conventional MR imaging. However, damage may be present below the capability of conventional MR imaging. For example, in other sports with a high incidence of repetitive head trauma (eg, American football), researchers have established the existence of chronic traumatic encephalopathy during postmortem examinations, which can only be seen under the microscope. ${ }^{19}$ Therefore, any damage evident on MR imaging likely represents the "tip of the iceberg," with much greater microscopic damage extending beyond any visible damage. For many fighters, it is possible that damage and dysfunction accumulate within this microscopic range, which could explain the discrepancy between known mild traumatic brain injury and MR images with clinically normal findings. Some portion of this range could be explored with higher field MR imaging (eg, 7T MR imaging with higher resolution and sensitivity to susceptibility effects) or with advanced MR imaging techniques such as high-resolution DTI. ${ }^{20}$

In our study, the $\mathrm{CMH}$ prevalence among fighters was $4.2 \%$; this is lower than the prevalence observed in previous studies $(7.1 \% \text { and } 9.5 \%)^{4,5}$ and was not statistically significant from that in our controls. This finding is likely in part due to the study being underpowered with a relatively small number of controls versus fighters, as supported by post hoc power analysis with an $\alpha$ of .05 that showed a power $(1-\beta)$ of $18.5 \%$. Generally, a power of $80 \%$ is considered adequate in most cases and would have required around double the control population to achieve adequate power, given an $\alpha$ of .05 and an unchanged incidence of $\mathrm{CMH}$ in fighters and controls. In regard to the raw percentage $\mathrm{CMH}$, a comparison study of retired National Football League players also demonstrated a prevalence of $9 \% .{ }^{21}$ The prevalence in our study may have been lower because we excluded susceptibility-positive healthy variants such as capillary telangiectasia and vascular malformations and nontraumatic pathologies such as cavernous malformations. If we had included these findings, the prevalence of $\mathrm{CMH}$ would have been $7.9 \%$. The type of imaging sequence used may also have played a role. $\mathrm{T} 2{ }^{*}$ and $\mathrm{SWI}$ are most commonly used to assess for the presence of $\mathrm{CMH}$. The higher prevalence of $\mathrm{CMH}$ observed by Hasiloglu et $\mathrm{al}^{5}$ may have been linked to their use of SWI, which is a newer and more sensitive sequence than $\mathrm{T} 2 *$ imaging. 


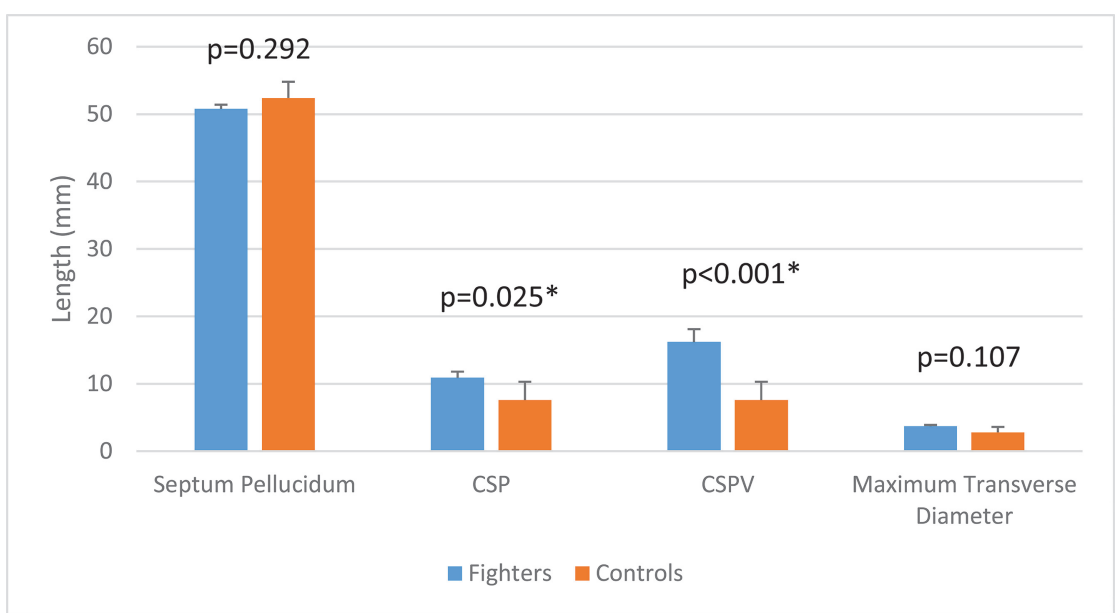

FIG 7. Septum pellucidum length, cavum septum pellucidum length, cavum septum pellucidum plus cavum vergae length, and maximum transverse diameter of the CSP in fighters versus controls.

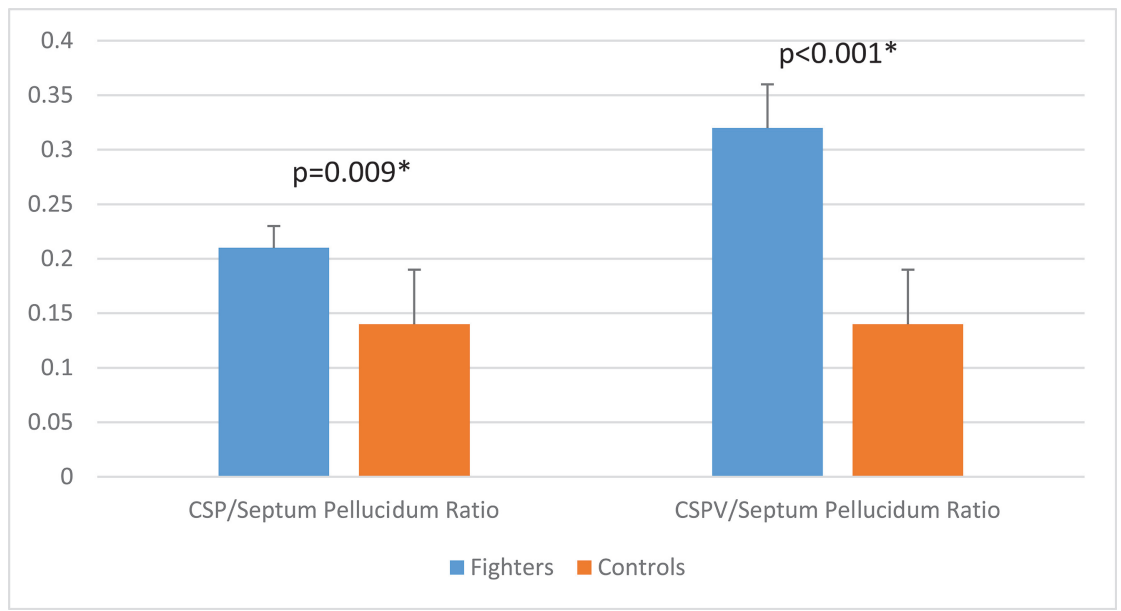

FIG 8. Cavum septum pellucidum and cavum septum pellucidum plus cavum vergae to septum pellucidum ratios in fighters versus controls.

The earliest studies to assess the occurrence of CSP in boxers used pneumoencephalography and found evidence of CSP in 6 of 9 boxers $(67 \%){ }^{22}$ a prevalence slightly higher than we observed in our study (53\%). In studies of American football players, Koerte et $\mathrm{al}^{14}$ and Gardner et $\mathrm{al}^{2}$ observed a CSP prevalence of $92 \%$ and $94 \%$, respectively. In addition, their prevalence of CSP in healthy controls was $57 \%$ and $18 \%$, respectively, with only the latter value comparable with our prevalence of $20 \%$. These differences may be partially explained by differences between the sports in the mechanism of head trauma; boxing blows to the head cause a rotational acceleration, whereas football blows to the head cause a linear acceleration. Other unknown mechanisms could also explain these differences, including genetic differences related to athlete selection. The mean age of each patient population may have also affected the results. The cohort of 72 retired football players in the study by Koerte et $\mathrm{al}^{14}$ had a higher mean age of 57 years compared with the mean patient age in our study (30 years). The age-dependent prevalence of CSP was illustrated in a large postmortem series of 1032 human brains (from nontraumatic brain injury victims), which demonstrated a CSP prevalence of $18 \%$ for boys younger than 10 years of age, 13\% for men 25-35 years of age (similar to our age group of controls at 20\%), and 24\% for men older than 50 years of age. ${ }^{23}$ Another postmortem series demonstrated a CSP prevalence of $18 \%,{ }^{24}$ whereas an MR imaging study of incidental findings of CSP in the pediatric population demonstrated a much lower prevalence of $1.14 \%$, with a mean patient age of 15 years.

These factors do not entirely explain the widely varying range of CSP prevalence observed in previous studies, however. For example, 2 previous MR imaging studies demonstrated a CSP prevalence in adults of $2.1 \%{ }^{25}$ and $68 \% .{ }^{26}$ In another study among football players, the CSP prevalence was 7\%, but the researchers included only large CSPs. ${ }^{21}$ This finding suggests that there may be considerable variation in how CSP has been defined in the literature. In our study, most CSPs were very small, appearing as small triangles or trapezoids just posterior to the genu of the corpus callosum (an average length of $10.9 \mathrm{~mm}$ in fighters). For future investigations, it would be helpful to derive a consensus opinion regarding size definitions for CSP.

The mechanism for increased CSP/CV prevalence and length with head trauma is still unknown. Pathologists have described 4 types of cava, including noncommunicating and communicating, further complicating the issue. ${ }^{24}$ One theory for the increase in length and prevalence of CSP/CV among patients with head trauma is that transient increased intracranial pressure results in passage of CSF through small tears in septal leaflets. ${ }^{10}$ Such tears were described in the postmortem examination of a former boxer as multiple perforations of the septal leaflets with a latticelike appearance. ${ }^{22}$ These tears could be accentuated by shear forces resulting from rapid rotation of the head, allowing CSF to enter the potential space of the septum pellucidum and slowly dissect a cavity. A second theory involves ex vacuo expansion of the potential space in the septum pellucidum due to central volume loss caused by repeated trauma. ${ }^{2,27}$ Future research might benefit from dedicated microscopic postmortem examinations of former athletes.

An interesting hypothesis that may explain the disparity of published CSP prevalence is that traumatic brain injury does not necessarily increase the prevalence of CSP, but the size. Using MR imaging in a pediatric cohort of 98 survivors of traumatic brain injury and 34 healthy controls, Silk et $\mathrm{al}^{28}$ concluded that there was no statistical difference between groups in the prevalence of CSP; however, CSPs were larger among patients with head trauma than among controls. In a similar postmortem study of patients with and without head trauma, the CSP prevalence was 38\% and 
$54 \%$, respectively. ${ }^{29}$ However, patients with head trauma demonstrated a distinct morphology of CSP termed a "cleft cavum," which was comorbid with diffuse axonal injury and represented $13 \%$ of all head trauma victims. The researchers suggested that this finding represents the acute effect of severe head trauma superimposed on an underlying baseline prevalence of nontraumatic CSP.

In our study, the prevalence of NSWMC was similar between fighters and controls; this finding suggests that no sequelae from repeated head trauma manifested as focal FLAIR hyperintensity. A recent study of college ice hockey players also found no evidence of new FLAIR lesions in patients with concussions, ${ }^{30}$ and in a study of 46 military veterans with mild traumatic brain injuries, Clark et $\mathrm{al}^{31}$ found that there was no significant increased prevalence of FLAIR WM lesions in patients versus controls. These findings suggest that standard MR imaging sequences such as FLAIR are not useful for the diagnosis of mild traumatic brain injury, ${ }^{32}$ perhaps because the size of the focal traumatic lesions is too small to be visible on these sequences.

This study had several limitations, including the relative imbalance between the large number of fighters and the smaller number of healthy controls. A greater number of controls would have increased the significance of our results, particularly in the case of $\mathrm{CMH}$, which has a low baseline prevalence. There are only a few relevant studies in the literature that have a large number of healthy controls imaged for $\mathrm{CMH}$. In particular, the studies of Hähnel at $\mathrm{al}^{4}$ and Hasiloglu et $\mathrm{al}^{5}$ together imaged 58 controls, none of whom had any $\mathrm{CMH}$. Although many other studies reported higher numbers of controls, these studies were not applicable because of their use of $\mathrm{T}^{\star}{ }^{\star}$ gradient recalled-echo sequences rather than SWI, ${ }^{33}$ poor age matches (typically elderly controls), or underlying disease states such as hypertension, degenerative disease, multiple sclerosis, and amyloid angiopathy. ${ }^{34-37}$

\section{CONCLUSIONS}

This is a large study of conventional MR imaging findings in a cohort of professional fighters with known repetitive head trauma, all scanned with the same 3T MR imaging scanner and protocol. We observed an increased prevalence of CSP and CSPV in fighters versus controls. The prevalence of $\mathrm{CMH}$ was also increased in fighters compared with controls, though this was not statistically significant, and may in part be due to underpowering of the study from a relatively lower number of controls. The prevalence of NSWMCs was also not significantly higher in fighters than in controls.

Disclosures: Jonathan K. Lee-RELATED: Grant: Ultimate Fighting Championship, Spike TV/Bellator MMA, Top Rank, Haymon Boxing, Golden Boy Promotions, Lincy Foundation/UCLA Dream Fund, and HBO.* Charles Bernick—RELATED: Grant: Ultimate Fighting Championship, Spike TV, Top Rank, Haymon Boxing, Golden Boy, HBO, Lincy Foundation/UCLA Dream Fund, Comments: These entities provide ongoing support for the Professional Fighters Brain Health Study from which the data for this article were acquired*; UNRELATED: Payment for Lectures Including Service on Speakers Bureaus: Allergen Plc. Michael T. Modic-UNRELATED: Grants/Grants Pending: Ultimate Fighting Championship, Spike TV/Bellator MMA, Top Rank, Haymon Boxing, Golden Boy Promotions, Lincy Foundation/UCLA Dream Fund, and HBO.* Stephen E. Jones—RELATED: Grant: Ultimate Fighting Championship, Spike TV/Bellator MMA, Top Rank, Haymon Boxing, Golden Boy Promotions, Lincy Foundation/UCLA Dream Fund, and HBO*; UNRELATED: Grants/Grants Pending: National Institutes of Health*; Payment for Lectures Including Service on Speakers Bureaus: Siemens, Monteris, RadNet, Cleveland Clinic lectures. *Money paid to the institution.

\section{REFERENCES}

1. Bodensteiner JB, Schaefer GB. Dementia pugilistica and cavum septi pellucidi: born to box? Sports Med 1997;24:361-65 CrossRef Medline

2. Gardner RC, Hess CP, Brus-Ramer M, et al. Cavum septum pellucidum in retired American pro-football players. J Neurotrauma 2016; 33:157-61 CrossRef Medline

3. Haglund Y, Bergstrand G. Does Swedish amateur boxing lead to chronic brain damage? 2: a retrospective study with CT and MRI. Acta Neurol Scand 1990;82:297-302 Medline

4. Hähnel S, Stippich C, Weber I, et al. Prevalence of cerebral microhemorrhages in amateur boxers as detected by 3T MR imaging. AJNR Am J Neuroradiol 2008;29:388-91 CrossRef Medline

5. Hasiloglu ZI, Albayram S, Selcuk H, et al. Cerebral microhemorrhages detected by susceptibility-weighted imaging in amateur boxers. AJNR Am J Neuroradiol 2011;32:99-102 CrossRef Medline

6. Jordan $\mathrm{BD}$, Zimmerman $\mathrm{RD}$. Computed tomography and magnetic resonance imaging comparisons in boxers. JAMA 1990;263: 1670-74 Medline

7. Koerte IK, Ertl-Wagner B, Reiser M, et al. White matter integrity in the brains of professional soccer players without a symptomatic concussion. JAMA 2012;308:1859-61 CrossRef Medline

8. Orrison WW, Hanson EH, Alamo T, et al. Traumatic brain injury: a review and high-field MRI findings in $\mathbf{1 0 0}$ unarmed combatants using a literature-based checklist approach. J Neurotrauma 2009;26: 689-701 CrossRef Medline

9. Zhang L, Heier LA, Zimmerman RD, et al. Diffusion anisotropy changes in the brains of professional boxers. AJNR Am J Neuroradiol 2006;27:2000-04 Medline

10. Aviv RI, Tomlinson G, Kendall B, et al. Cavum septi pellucidi in boxers. Can Assoc Radiol J 2010;61:29-32; quiz 21-22 CrossRef Medline

11. Levin HS, Lippold SC, Goldman A, et al. Neurobehavioral functioning and magnetic resonance imaging findings in young boxers. J Neurosurg 1987;67:657-67 CrossRef Medline

12. Bernick C, Banks SJ, Shin W, et al. Repeated head trauma is associated with smaller thalamic volumes and slower processing speed: the Professional Fighters' Brain Health Study. Br J Sports Med 2015; 49:1007-11 CrossRef Medline

13. Costanza A, Weber K, Gandy S, et al. Review: contact sport-related chronic traumatic encephalopathy in the elderly-clinical expression and structural substrates. Neuropathol Appl Neurobiol 2011;37: 570-84 CrossRef Medline

14. Koerte IK, Hufschmidt J, Muehlmann M, et al. Cavum septi pellucidi in symptomatic former professional football players. J Neurotrauma 2016;33:346-53 CrossRef Medline

15. Bernick C, Banks S, Phillips M, et al. Professional fighters brain health study: rationale and methods. Am J Epidemiol 2013;178: 280-86 CrossRef Medline

16. Fazekas F, Chawluk JB, Alavi A, et al. MR signal abnormalities at $\mathbf{1 . 5}$ $\mathrm{T}$ in Alzheimer's dementia and normal aging. AJR Am J Roentgenol 1987;149:351-56 CrossRef Medline

17. Cassasa CB. Multiple traumatic cerebral hemorrhages. Proc New York Path Soc 1924;24:101

18. Martland HS. Punch drunk. JAMA 1928;91:1103-07

19. Omalu BI, DeKosky ST, Minster RL, et al. Chronic traumatic encephalopathy in a National Football League player. Neurosurgery 2006;58:E1003 CrossRef Medline

20. Shin W, Mahmoud SY, Sakaie K, et al. Diffusion measures indicate fight exposure-related damage to cerebral white matter in boxers and mixed martial arts fighters. AJNR Am J Neuroradiol 2014;35:285-90 CrossRef Medline

21. Casson IR, Viano DC, Haacke EM, et al. Is there chronic brain damage in retired NFL players? Neuroradiology, neuropsychology, and neurology examinations of 45 retired players. Sports Health 2014;6: 384-95 CrossRef Medline 
22. Mawdsley C, Ferguson FR. Neurologic disease in boxers. Lancet 1963;2:795-801 Medline

23. Schwidde JT. Incidence of cavum septi pellucidi and cavum vergae in 1,032 human brains. AMA Arch Neurol Psychiatry 1952;67:625-32 CrossRef Medline

24. Oteruelo FT. On the cavum septi pellucidi and the cavum vergae. Anat Anz 1986;162:271-78 Medline

25. Pauling KJ, Bodensteiner JB, Hogg JP, et al. Does selection bias determine the prevalence of the cavum septi pellucidi? Pediatr Neurol 1998;19:195-98 CrossRef Medline

26. Born CM, Meisenzahl EM, Frodl T, et al. The septum pellucidum and its variant: an MRI study. Eur Arch Psychiatry Clin Neurosci 2004; 254:295-302 Medline

27. Banks SJ, Mayer B, Obuchowski N, et al. Impulsiveness in professional fighters. J Neuropsychiatry Clin Neurosci 2014;26:44-50 CrossRef Medline

28. Silk T, Beare R, Crossley L, et al. Cavum septum pellucidum in pediatric traumatic brain injury. Psychiatry Res 2013;213:186-92 CrossRef Medline

29. Pittella JE, Gusmão S. Cleft cavum of the septum pellucidum in victims of fatal road traffic accidents: a distinct type of cavum associated with severe diffuse axonal injury. Surg Neurol 2005;63(suppl 1):S30-34; discussion S34-35 CrossRef Medline

30. Jarrett M, Tam R, Hernández-Torres E, et al. A prospective pilot investigation of brain volume, white matter hyperintensities, and hemorrhagic lesions after mild traumatic brain injury. Front Neurol 2016;7:11 CrossRef Medline
31. Clark AL, Sorg SF, Schiehser DM, et al. Deep white matter hyperintensities affect verbal memory independent of PTSD symptoms in veterans with mild traumatic brain injury. Brain Inj 2016;30:864-71 CrossRef Medline

32. Hughes DG, Jackson A, Mason DL, et al. Abnormalities on magnetic resonance imaging seen acutely following mild traumatic brain injury: correlation with neuropsychological tests and delayed recovery. Neuroradiology 2004;46:550-58 Medline

33. Cordonnier C, Al-Shahi Salman R, Wardlaw J. Spontaneous brain microbleeds: systematic review, subgroup analyses and standards for study design and reporting. Brain 2007;130:1988-2003 CrossRef Medline

34. Huang YL, Kuo YS, Tseng YC, et al. Susceptibility-weighted MRI in mild traumatic brain injury. Neurology 2015;84:580-85 CrossRef Medline

35. Koerte IK, Lin AP, Willems A, et al. A review of neuroimaging findings in repetitive brain trauma. Brain Pathol 2015;25:318-49 CrossRef Medline

36. Vernooij MW, Ikram MA, Tanghe HL, et al. Incidental findings on brain MRI in the general population. $N$ Engl J Med 2007;357: 1821-28 CrossRef Medline

37. Qureshi AI, Chughtai M, Malik AA, et al. Incidental asymptomatic intracerebral hemorrhages and risk of subsequent cardiovascular events and cognitive decline in elderly persons. J Stroke Cerebrovasc Dis 2015;24:1217-22 CrossRef Medline 